\title{
The influence of Reverse osmosis desalination in a combination with pump storage on the penetration of wind and PV energy: A case study for Jordan
}

\author{
T. Novosel, B. Ćosić, G. Krajačić, N. Duić, T. Pukšec \\ Faculty of Mechanical Engineering and Naval Architecture, Department of Energy, Power \\ Engineering and Environment \\ University of Zagreb, Zagreb, Croatia \\ e-mail: tomislav.novosel@fsb.hr, boris.cosic@fsb.hr, goran.krajacic@fsb.hr, \\ neven.duic@fsb.hr, tomislav.puksec@fsb.hr
}

\author{
M. S. Mohsen \\ American University of Ras Al Khaimah \\ PO Box: 10021; Ras Al Khaimah; United Arab Emirates \\ e-mail: mousa.mohsen@aurak.ae \\ M. S. Ashhab, A. K. Ababneh \\ Department of Mechanical Engineering \\ Hashemite University, Zarqa, Jordan \\ e-mail: sami@hu.edu.jo, ababneh_hu@hu.edu.jo
}

\begin{abstract}
Water resources are a crucial problem for a number of arid countries. One possible solution for this issue is the implementation of desalination but its utilization can greatly increase the demand for electricity. An important concept for a wide scale implementation of desalination is the integration of water and energy resources.

Jordan is currently one of the most water deprived countries in the world. It is also a country very rich in renewable energy sources but almost no utilization of that potential. A combination of desalination, pump storage that utilize the produced brine and renewable energy sources could solve both issues. The desalination plants could produce enough water to ensure the supply for Jordan's ever growing population while the use of wind and solar power could provide much needed electricity and reduce the need for imported fossil fuels as well as $\mathrm{CO} 2$ emissions.

The goal of this paper is to evaluate the impact of desalination in a combination with pump storage that utilizes the produced brine on the penetration of intermittent renewable energy sources in an energy system. The analysis has been conducted on a case study for the country of Jordan using the EnergyPLAN advanced energy system analyses tool.
\end{abstract}

\section{Keywords}

Jordan; renewable energy; desalination; EnergyPLAN

\section{INTRODUCTION}

The integration of water and energy systems is a very important concept for the development of arid countries which are often affected by water scarcity. The combination of desalination and renewable energy sources (RES) can have a positive effect on the system as a whole. One country that could benefit from such a concept is the country of Jordan which is currently facing three major issues. 
First of all, almost all of the produced electricity in Jordan comes from imported fossil fuels. Approximately $90 \%$ comes from natural gas while the rest comes mostly from oil and a negligible amount from renewables [1]. This situation is becoming quite expensive for the country. The Jordanian annual fuel bill exceeds 3 billion US\$, which is approximately $20 \%$ of its GDP for the year 2011 [2]. This could become an even bigger problem since Jordan's official energy strategy predicts an annual increase in the consumption of electricity by $7.4 \%$ annually until 2020 [3] and the latest predictions say that the population in Jordan is likely to increase by $50 \%$ until the year 2030 [4]. Aside from the great economic expense that comes from their import, the production of electricity from fossil fuels also has a profoundly negative impact on the environment. This doesn't have to be so. Jordan is a country rich in renewable energy sources (RES), namely wind and solar. Several studies have shown a high potential for the economically viable utilization of both wind [5], [6] and [7] and solar power [5], [8] and [9]. In some cases the payback period for wind power was as low as 6 [10] and for solar power as low as 2.3 years [11]. The problem with a high level of penetration of these types of energy sources is the intermittent nature of their operation. Since their production is dependent on atmospheric conditions it cannot be fully controlled. Because of this, critical excess of electricity production (CEEP) can become a problem, especially during times of high production and low consumption.

The second problem Jordan is facing is the extreme water scarcity. Jordan is the World's fourth most water deprived country [12] with an annual consumption of around $150 \mathrm{~m}^{3}$ of fresh water per capita [12], [13], [14] and [15] which is far below the severe international poverty line of $500 \mathrm{~m}^{3}$ per capita annually [16]. In order to mitigate this, desalination will have to be used. The desalination units can be designed in such a way to incorporate brine operated pump hydro storage (BoPHS) and so help reduce CEEP. There is already a large scale desalination project proposed for Jordan [17] but this one is designed to be as energy efficient as possible without the idea to help increase the penetration of renewables into the Jordanian energy system. In one of our previous works a system that utilizes desalination in order to increase the penetration of renewables into the Jordanian energy system has already been proposed, both trough the flexibility of the desalination system as well as with BoPHS on the brine side of the desalination unit [18] and [19].

The third problem that is affecting Jordan is the steady decline of the Dead Sea's water level caused by the intense agricultural activity along the shores of the river Jordan [17]. This poses a potential ecological disaster for the surrounding area in the form of soil erosion, land degradation and the collapse of sinkhole fields as observed in [20]. This problem can be mitigated with the use of the brine produced from the desalination units.

The integrated use of desalination in a combination with BoPHS and RES can help to greatly reduce all three mentioned problems. First of all the flexible nature of desalination units and the integrated BoPHS can help increase the penetration of RES in the system and that way reduce the dependence on imported energy. Secondly, the produced fresh water can be used to satisfy Jordan's ever increasing water demand and finally, the produced brine can be used to help prevent the decline of the Dead Sea's water level.

Reverse osmosis (RO) desalinization is the most wide spread sea water desalinization technology in use today. It has a relatively high electricity consumption but modern medium to large capacity sea water desalinization plants have a consumption lower than $2 \mathrm{kWh} / \mathrm{m}^{3}$, for example a system installed in Sal Island, Cape Verde [21]. RO desalinization plants are highly flexible [22] and are because of that very suitable for use in conjunction with renewable energy 
sources. The benefits of combining wind power [23] and [24] and PV [25], [26] and [27] with reverse osmosis desalinization plants has already been discussed by many authors.

The goal of this paper is to analyse the impact of RO desalination units on the potential for the penetration of intermittent RES in an energy system. The effect of the flexibility of the RO desalination units as well as the storage capacity of the BoPHS system will be evaluated. The analysis has been conducted on a case study for the country of Jordan for multiple scenarios with different penetrations of RES, desalination BoPHS units and flexibility of the desalination units. The results of the analysis include CEEP, fuel consumption excluding RES and $\mathrm{CO}_{2}$ emissions. The EnergyPLAN advanced energy system analyses tool has been used for this analysis [28]. Even though the economic aspect of such a project is very important this work will not address it. The cost of a similar investment described in [17] has been estimated to 5 billion US\$ with an annual operational cost of 5 million US\$.

\subsection{Jordan's energy system}

In 2009 Jordan had a population of 5.95 million and a GPD of 35.38 billion USD [1]. The total primary energy supply (PES) for that year was $80.52 \mathrm{TWh}, 98 \%$ of which came from fossil fuels [1]. As it was already noted above, Jordan is highly dependent on imported energy as it imports over $95 \%$ of all of its primary energy [1]. Figure 1 shows the distribution of Jordan's primary energy supply. As can be seen from the pie chart, 53\% of Jordan's primary energy comes from oil, $45 \%$ from natural gas and $2 \%$ from renewables.

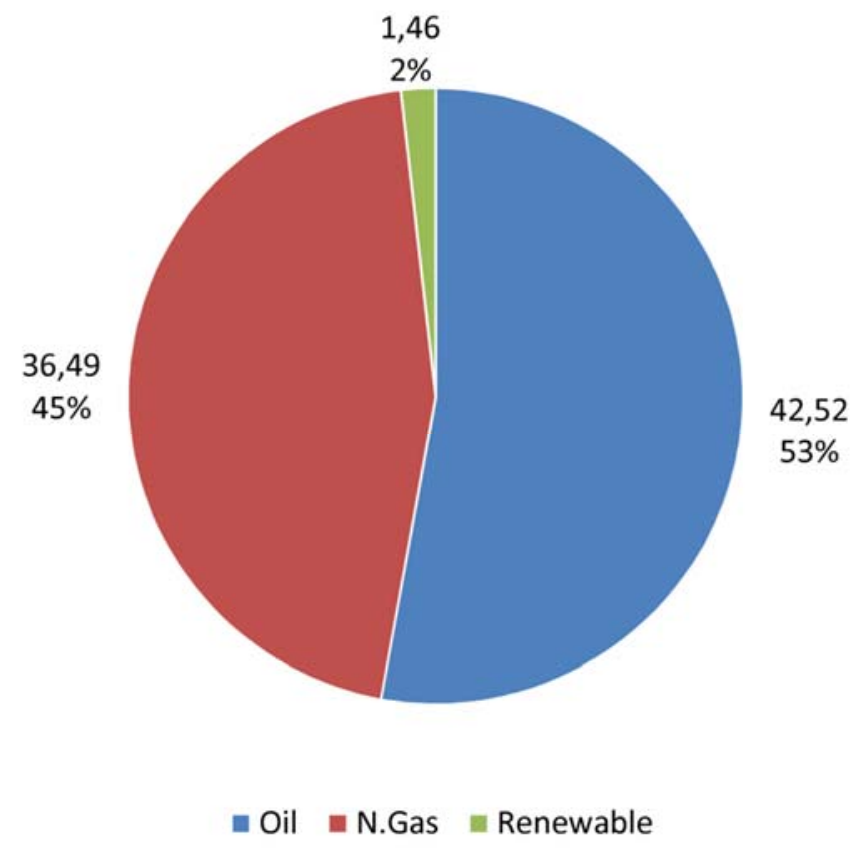

Figure 1 Jordan's PES in TWh and share of fuels in total PES [1]

In 2009 Jordan's electricity consumption was 14.516 TWh [1]. $40.9 \%$ of that consumption was in the domestic sector, $25.1 \%$ in industry and $14.8 \%$ in the commercial sector. Table 1 shows the distribution of this demand by sectors [29]. Table 2 shows the installed capacities in Jordan's electrical system. As the table shows, the majority of the installed electrical power comes from steam power plants, almost $39 \%$, and combined cycle power plants, close to $38 \%$. It should also be noted that of the $2603 \mathrm{MW}$ of installed power, $2586 \mathrm{MW}$ came from fossil fuel power plants, which is $99.35 \%$. The total amount of electricity generated in the country was $14.272 \mathrm{TWh}$, $0.363 \mathrm{TWh}$ has been imported from Egypt and 0.02 TWh from Syria [29]. 
Table 1 Electricity consumption by sectors [29]

\begin{tabular}{ll}
\hline Sector & Consumption weight [\%] \\
\hline Domestic & $40.9 \%$ \\
Industrial & $25.1 \%$ \\
Commercial & $16.6 \%$ \\
Water pumping & $14.8 \%$ \\
Street lighting & $2.6 \%$ \\
\hline
\end{tabular}

Table 2 Installed capacities in Jordan's electrical system in 2009 [MW] [29]

\begin{tabular}{llllllll}
\hline Steam & $\begin{array}{l}\text { Diesel } \\
\text { Engines }\end{array}$ & $\begin{array}{l}\text { Gas } \\
\text { Turbines }\end{array}$ & $\begin{array}{l}\text { Combined } \\
\text { Cycle }\end{array}$ & $\begin{array}{l}\text { Hydro } \\
\text { Units }\end{array}$ & $\begin{array}{l}\text { Wind } \\
\text { Energy }\end{array}$ & Biogas & Total \\
\hline $\mathbf{1 0 1 3}$ & 4 & 589 & 980 & 12 & 1 & 4 & 2603 \\
\hline
\end{tabular}

\section{METHODS}

The Jordanian energy system has been recreated using EnergyPLAN for the purpose of this paper. EnergyPLAN is a deterministic input output computer modelling tool that creates an annual analysis of an energy system with a time step of one hour. The required inputs include the total demands and demand curves for electricity, installed capacities and efficiencies of different types of energy producers and energy storage technologies, fuel mix, hourly distribution of energy production from intermittent sources like wind and solar, the energy demands for the different sectors and different regulation strategies. The results of the model, the outputs, are the energy balances, annual and hourly productions of energy and CEEP, fuel consumptions, total cost of the system, $\mathrm{CO}_{2}$ emissions and so on.

Since it is a deterministic model it will always give the same results for the same set of input parameters. In order to speed up the calculation process EnergyPLAN uses analytical programming instead of iterations and aggregated data inputs for different units in the same sector. It optimizes the operation of the system, not the investments or emissions but it does offer the possibility to utilize different regulation strategies, to be exact, four technical optimization strategies and three market economic optimization strategies. The technical regulation strategy - Balancing both heat demand and electricity demands has been used to create the base model and the scenarios for this paper. The selection of a type of technical optimization strategy is not so important for the case of Jordan since it mostly deals with the balancing of the electrical load and heat production from combined heat and power plants (CHP) units which are not present here. Figure 2 presents a schematic diagram of EnergyPLAN. 


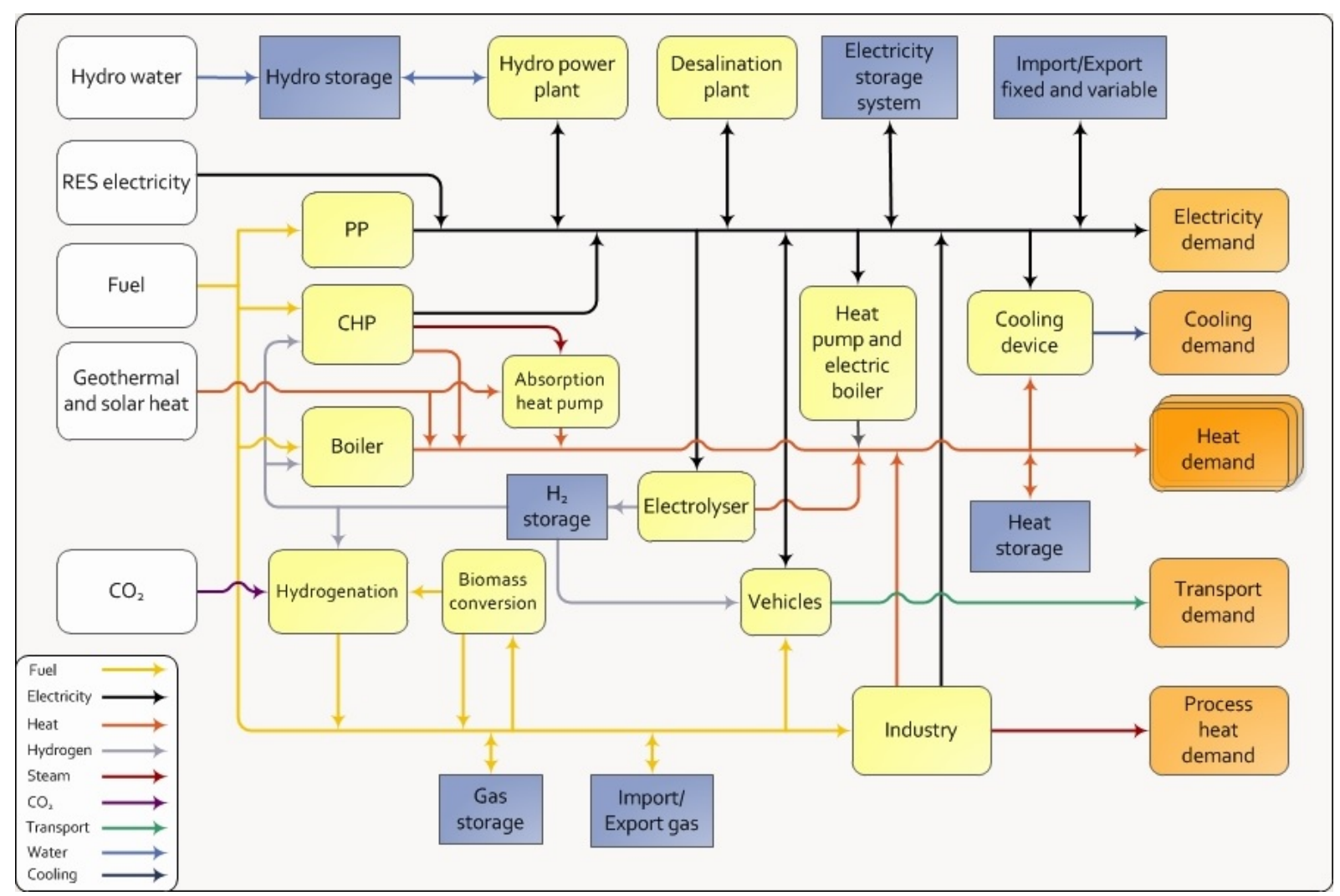

Figure 2 EnergyPLAN model [28]

EnergyPLAN is specialized in the large scale integration of RES in energy systems [30] and [31], analysis of the impact of the transport sector, especially electric vehicles, on the energy system [32] and [33], the optimal combination of RES [34] and the implementation of CHP units in energy systems [35]. It has already been used to recreate many different energy systems and devise numerous energy scenarios. For example, authors of [30] and [36] used the model to simulate different scenarios for the Macedonian energy system. In [35] and [37] EnergyPLAN has been used to model the Danish energy system and to analyze the potential for the integration of RES. The authors of [38] used both the EnergyPLAN and the $\mathrm{H}_{2} \mathrm{RES}$ [39] models to recreate the Croatian energy system and plan a $100 \%$ energy independent scenario.

The desalination is a new module implemented into the EnergyPLAN version 11. The inputs necessary to run a scenario with desalination are amongst others the total annual fresh water demand and hourly demand curve, fresh water storage, energy efficiency of the pumps, efficiency of the desalination process, capacity of the desalination plant and the data regarding the pump hydro storage using the produced brine. The desalination module, its operation and integration into the electricity system has been described in great detail in the EnergyPLAN manual [40], which is available online, and in [19].

\section{SCENARIOS}

The first step in order to analyze the impact of desalination on the potential for the penetration of RES in the Jordanian energy system is the creation of a reference model. The hourly electrical load curve was obtained from the Jordanian National Electric Power Company (NEPCO) [41] and the installed capacities for the year 2009 were taken from NEPCOs annual report [29]. The fuel mix for the installed thermal power plants and the energy consumption in the residential, industrial, commercial and transport sectors were all taken from the International Energy 
Agency (IEA) [1]. The meteorological data including hourly wind speeds and solar radiation was obtained with the use of the computer program METEONORM [42]. The hourly data for wind speed and global radiation on a horizontal plane for the first week of June can be seen in Figure 3.
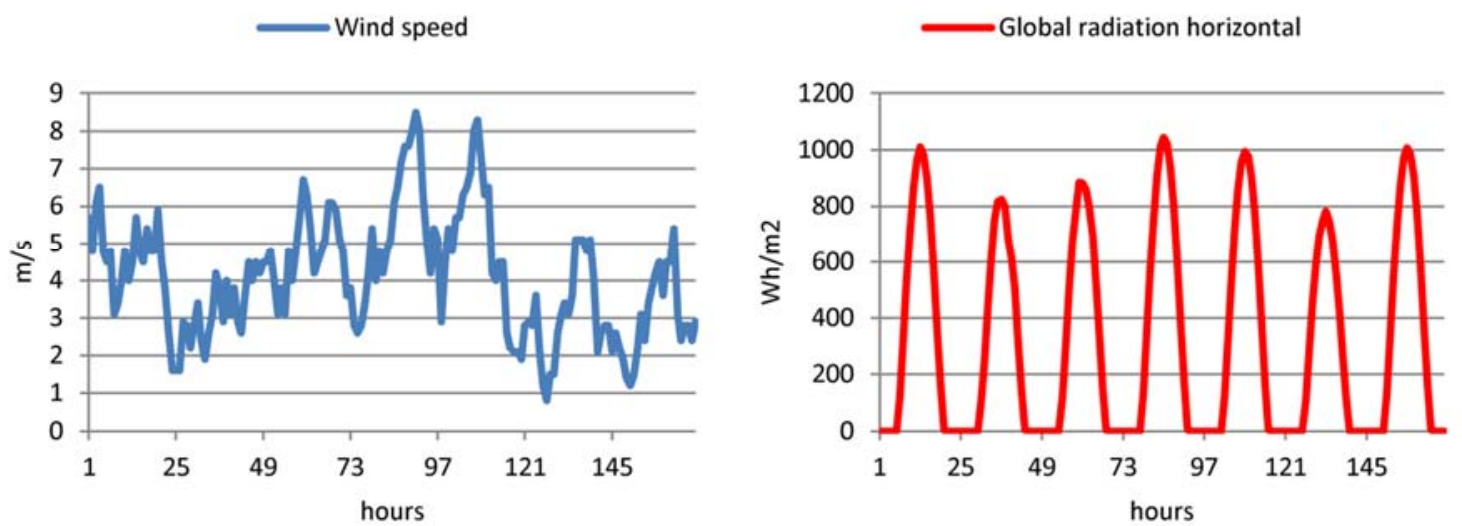

Figure 3 METEONORM data

The desalination system presented in this work is similar to the one proposed in [17] but it has a few key differences. The water from the Red Sea would be pumped to an elevation of approximately $1000 \mathrm{~m}$ and transported to the desalination plants close to the Dead Sea. The salt water would then be pumped through the desalination unit. The produced fresh water would be stored in a fresh water storage system and pumped to where it is needed (for the purpose of this work the destination is Amman) and the brine would be collected in a brine storage system and used for BoPHS with the Dead Sea as the lower storage. Figure 4 presents a block diagram of the proposed desalination system. This configuration consumes more energy per produced $\mathrm{m}^{3}$ of fresh water than the one in [17], but its configuration allows for the utilization of the brine storage as BoPHS in a combination with the Dead Sea which can in turn increase the penetration of RES in the system. The proposed system could deliver $570 \mathrm{Mm}^{3}$ of fresh water annually to Jordan, same as the one proposed in [17], and the minimum capacity of the desalination plant is $64960 \mathrm{~m}^{3}$ of fresh water per hour in this case. This would mean a little over $95 \mathrm{~m}^{3}$ of fresh water per capita annually for Jordan which would bring the total consumption of water to 245 $\mathrm{m}^{3}$ or an increase of $63 \%$. A constant hourly fresh water demand has been presumed since there is no data available for the hourly water consumption in Jordan. The utilization of desalination also increases the total electricity demand in the system from $14.516 \mathrm{TWh}$ annually to 21.768 TWh, an increase of $49.96 \%$. 


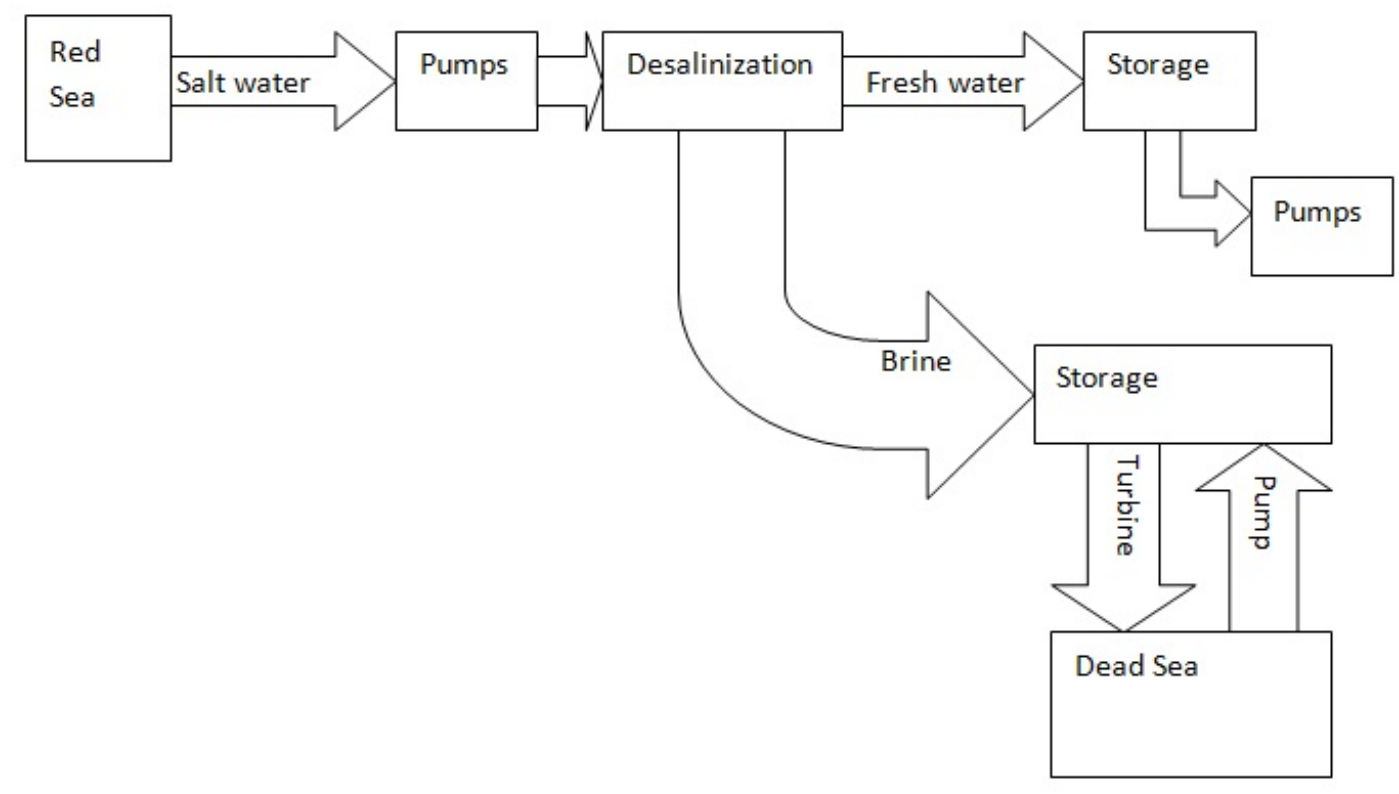

Figure 4 Desalination system

Two sets of 12 scenarios have been created for the purpose of this work. The first set presumes a desalination unit with a capacity of $65000 \mathrm{~m}^{3}$ of fresh water per hour and the second set a unit with a capacity of $97000 \mathrm{~m}^{3}$ of fresh water per hour. This means that the first unit allows almost no flexibility in its operation while the second one can vary its production since the installed capacity is $50 \%$ higher than the minimum necessary to satisfy the demand. Half of the scenarios have been created for the purpose of the analysis of the impact desalination has on the penetration of wind and half for PV. In both cases the scenarios represent one scenario with a desalination units with no BoPHS and five scenarios with desalination and a BoPHS with an installed power of $250 \mathrm{MW}, 500 \mathrm{MW}, 1000 \mathrm{MW}, 1500 \mathrm{MW}$ and $2000 \mathrm{MW}$ and a storage capacity of 6 hours, meaning $0.4 \mathrm{Mm}^{3}, 0.8 \mathrm{Mm}^{3}, 1.6 \mathrm{Mm}^{3}, 2.4 \mathrm{Mm}^{3}$ and $3.2 \mathrm{Mm}^{3}$ of brine storage. The penetration of both wind and PV power has been varied from $0 \%$ to $50 \%$ of the total electricity demand with a 5\% step. The analysed results include CEEP as a percentage of the total annual electricity demand, fuel consumption excluding RES in TWh and $\mathrm{CO}_{2}$ emissions in Mt. CEEP has additionally been compared to the reference scenario created with no desalination and no storage technologies.

All of the scenarios were created as a closed system (no import or export of electricity is allowed) by setting the transmission line capacity in EnergyPLAN to zero. This restriction has been applied to the reference scenario as well. This allows us to observe the influence of the desalination and BoPHS on the generation of CEEP with the increase of the penetration of intermittent RES more precisely. Aside from that, the political instability of the region as well as similar atmospheric conditions should encourage every region to pursue a sustainable and self-sufficient energy system. The technical regulation strategy 2 "Balancing both heat and electricity demand" has been used to create the scenarios. The minimum electrical load present in the Jordanian energy system for the observed year was $1040 \mathrm{MW}$ [41] or $40 \%$ of the total installed power of the condensing power plants in the country. For this reason the minimum power plant capacity (PPmin) has been set to $40 \%$. The minimum grid stabilization share has been set to $30 \%$. This means that at all times $30 \%$ of the produced electricity has to come from power plants that can provide ancillary services, or in other words, power plants whose output 
can be regulated freely for example condensing power plants, CHP units, accumulation hydro power plants and so on.

\section{RESULTS AND DISCUSSION}

The results of energy system analysis preformed for the created scenarios are presented in this chapter as well as the comparison of the created reference scenario with the data gathered from the IEA website [1].

\subsection{Model validation}

The reference model has been compared with the data obtained from the IEA website [1]. Table 3 presents this comparison. There is a slight difference in the fuel consumption of the power plants (PP). The reason behind this is that the model created for the purpose of this paper presents a closed system and Jordan did import $0.383 \mathrm{TWh}$ and export $0.139 \mathrm{TWh}$ of electricity in 2009, which is an equivalent of $1.075 \mathrm{TWh}$ of primary energy import and $0.39 \mathrm{TWh}$ of primary energy export [1]. The energy consumption of the transport, residential and industry sectors is virtually identical in both cases. Since EnergyPLAN doesn't support the distinction between the household and commercial sectors, they were both summed up and input into the "Individual" tab in the model. The consumption of energy for the agricultural, fishing and industry sectors has also been summed up and entered in the industry tab.

Table 3 Comparison of the reference model and the data from the IEA

\begin{tabular}{cccc}
\hline Energy consumption (TWh annually) & IEA [1] & EnergyPLAN & Difference \\
\hline PP N. gas & 35.88 & 36.49 & $1.7 \%$ \\
PP Oil & 3.9 & 3.97 & $1.8 \%$ \\
PP Biomass & 0.02 & 0.02 & $0 \%$ \\
Transport & 20.08 & 20.09 & $0.05 \%$ \\
Residential & 8.63 & 8.63 & $0 \%$ \\
Industry & 9.83 & 9.83 & $0 \%$ \\
\hline
\end{tabular}

\subsection{Results}

The results of the preformed analysis are presented in this section. Figure 5 shows CEEP in the described system in relation to the installed capacity of the BoPHS and electricity production from wind power and PV once for a standard desalination unit with a capacity of $65000 \mathrm{~m}^{3}$ of fresh water per hour (100\% capacity) and once for a flexible desalination unit with $97000 \mathrm{~m}^{3}$ of fresh water per hour ( $150 \%$ capacity). Aside from the 24 scenarios, the results for the penetration of wind power and PV in the reference scenario are also presented here. As it can be seen in Figure 5 (A) the utilization of desalination can somewhat increase the potential for the penetration of wind power in the system even without BoPHS. The results for the system with no BoPHS and for the one with the smallest unit with an installed power of $250 \mathrm{MW}$ are virtually identical. As it is expected the increase of the installed power and storage capacity of the BoPHS results in the reduction of CEEP from wind power. The CEEP in the reference scenario with a wind penetration of $50 \%$, meaning that $50 \%$ of the electricity demand is satisfied from wind power, equals $29.97 \%$ of the total electricity demand. For a system with a desalination unit and no BoPHS this value is $28.87 \%$, which is $1.1 \%$ lower than in the reference scenario. CEEP in a system with desalination and a BoPHS with an installed power of 2000 MW and storage capacity of $3.2 \mathrm{Mm}^{3}$ equals $22.08 \%$ of the electricity demand which is $7.89 \%$ less than the reference scenario for the same level of wind penetration. 
If we observe a scenario with CEEP equalling 5\% of the total annual electricity demand, the reference scenario could support wind penetration of less than $20 \%$ of the total annual electricity demand. The utilization of a desalination system without the use of BoPHS can increase this penetration to a little under $25 \%$ while the utilization of a BoPHS with an installed power of $2000 \mathrm{MW}$ could increase it further to a little over 30\%, as is presented in Figure 5. The value of $5 \%$ of CEEP has been chosen since it is usually more economical to tolerate a small amount of excess than to build storage capacities or other systems that will operate for a very limited period of time [43] and [44]
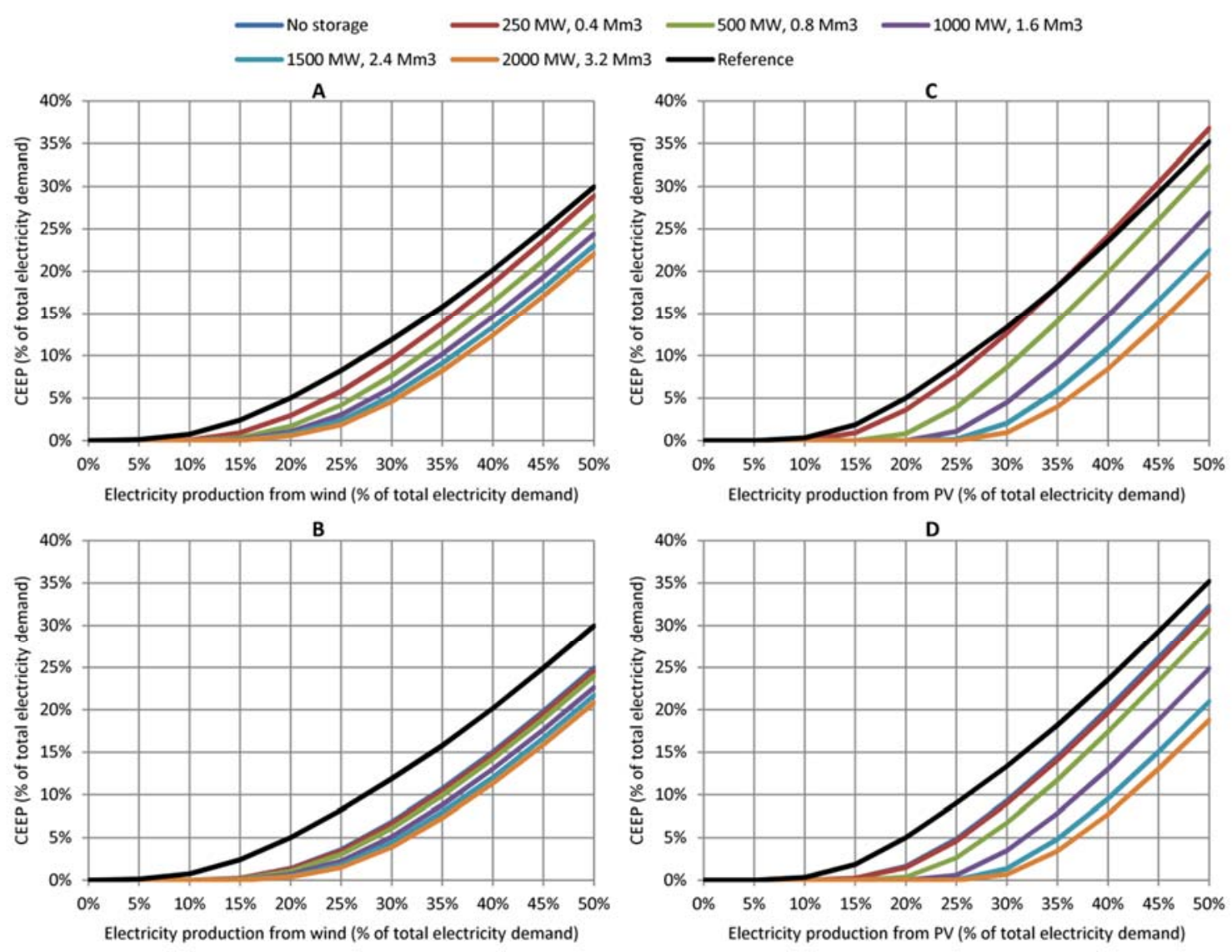

Figure 5 CEEP for scenarios with wind plus standard (A) and flexible desalination (B) and PV with standard (C) and flexible desalination (D)

The potential for the increase of the penetration of wind is even greater if we consider a flexible desalination unit. Figure 5 (B) presents the results for the analysis of CEEP for different levels of wind power penetration in systems with different capacities of BoPHS and a desalination unit with $150 \%$ of the capacity needed to satisfy the demand for fresh water. This increased capacity allows the desalination unit to operate flexibly and to adapt to the situation in the power grid and thus increases the potential for the penetration of intermittent RES. Again, as in the previous figure, CEEP in the reference scenario is presented here as well. There is also no notable difference between the scenario with no storage and a BoPHS with an installed power of $250 \mathrm{MW}$ and storage capacity of $0.4 \mathrm{Mm}^{3}$. CEEP in a system with a desalination unit and no storage and a wind penetration of $50 \%$ is $24.92 \%$, which is $5.05 \%$ less than the reference scenario for the same penetration and 3.95\% less than for the same scenario but with the standard desalination unit (as presented in Figure 5 (A)) and same wind penetration. In the case of the scenario with a desalination unit and a BoPHS with a power of $2000 \mathrm{MW}$ and storage capacity of $3.2 \mathrm{Mm}^{3}$ and wind penetration of $50 \%$, CEEP equals $20.84 \%$ which is $9.13 \%$ less 
than the reference scenario and $1.24 \%$ less than the same scenario but with a standard desalination unit for the same level of wind penetration.

If we again observe the situation with CEEP equalling 5\% of the total annual electricity demand but with a flexible desalination unit the potential wind penetration is even better. In comparison to the $20 \%$ of the reference scenario, the desalination system without the BoPHS can increase the penetration to roughly $27 \%$, while the utilization of a BoPHS with an installed power of $2000 \mathrm{MW}$ can increase this penetration to roughly $32 \%$.

Figure 5 (C) and Figure 5 (D) present the analysis of CEEP for the same scenarios presented earlier but for PV penetration. The increase of both the BoPHS and the capacity (flexibility) of the desalination plant increase the potential for the penetration of renewables. It can again be observed in Figure 5 (C) that the CEEP for the scenario with a desalination plant and no BoPHS and the smallest BoPHS observed are virtually identical for different penetrations of PV but only for the case when the desalination plant with a capacity of $100 \%$ (standard) is utilized. It can also be observed that the CEEP is higher in the case of a desalination unit with no BoPHS and the smallest BoPHS unit than for the reference scenario for PV penetrations higher than $35 \%$. This is not the case for a flexible desalination plant as can be seen in Figure 5 (D). CEEP ranges from $36.77 \%$ to $19.65 \%$ in a system with a desalination plant with a capacity of $100 \%$ and $50 \% \mathrm{PV}$ penetration while it is $35.2 \%$ for the reference scenario. In the case of a desalination plant with a capacity of $150 \%$ of the demand and PV penetration of $50 \%$, CEEP ranges from $32.31 \%$ to $18.77 \%$ which can be $16.43 \%$ less than the reference scenario if we observe the case with a BoPSH unit with a capacity of $2000 \mathrm{MW}$ and $3.2 \mathrm{Mm}^{3}$.

The reference scenario could tolerate a penetration of PV equalling $20 \%$ of the total annual electricity demand with a CEEP of $5 \%$. The utilization of a desalination plant and no BoPHS could increase this value to roughly $22 \%$ for a standard desalination unit with a capacity of $65000 \mathrm{~m}^{3}$ of fresh water per hour and $25 \%$ for a desalination unit with a capacity of $97000 \mathrm{~m}^{3}$ per hour. With a BoPHS the values increase to roughly $36 \%$ for the standard unit and roughly $37 \%$ for the flexible one.

Figure 6 presents the fuel consumption excluding RES for all 24 scenarios. As it was expected, a higher penetration of RES will decrease the fuel consumption in the system and the implementation of a larger BoPHS will have a higher influence as will the increase of the flexibility of the desalination plant. It can also be observed that the fuel consumption is virtually identical in the cases of no BoPHS storage and a BoPHS with a power of $250 \mathrm{MW}$ and a storage capacity of $0.4 \mathrm{Mm}^{3}$ for both wind and PV and for both of the desalination plants $(100 \%$ and $150 \%$ capacity). It can be seen that the fuel consumption starts to increase at higher levels of both wind and PV penetrations on all four of the presented figures. This is more obvious for PV (Figure $6(\mathrm{C})$ and (D)) than for wind (Figure $6(\mathrm{~A})$ and (B)). The reason for this is the minimum grid stabilization share that states that at any given time $30 \%$ of the produced electricity has to come from power plants that can provide ancillary services. This has already been mentioned in the chapter Scenarios. As the energy production from wind and PV reach a certain point, condensing thermal power plants have to work just to provide this grid stabilization and that is why this increase occurs. The scenario with the lowest fuel consumption is a system with a desalination plant with an installed capacity of $150 \%$, PV penetration of $40 \%$ and BoPHS with a power of $2000 \mathrm{MW}$. The total fuel consumption excluding RES is 75.08 TWh annually which is $3.89 \mathrm{TWh}$ less than the fuel consumption in the reference scenario. It should be stated that the energy consumption in the scenario with desalination is significantly higher than the reference scenario. If we observe the fuel consumption in relation to the total 
electricity demand than the fuel consumption for the scenario with desalination is $3.45 \mathrm{TWh}$ of fuel consumption per TWh of electricity demand, compared to 5.44 for the reference scenario. That is a difference of almost $37 \%$.
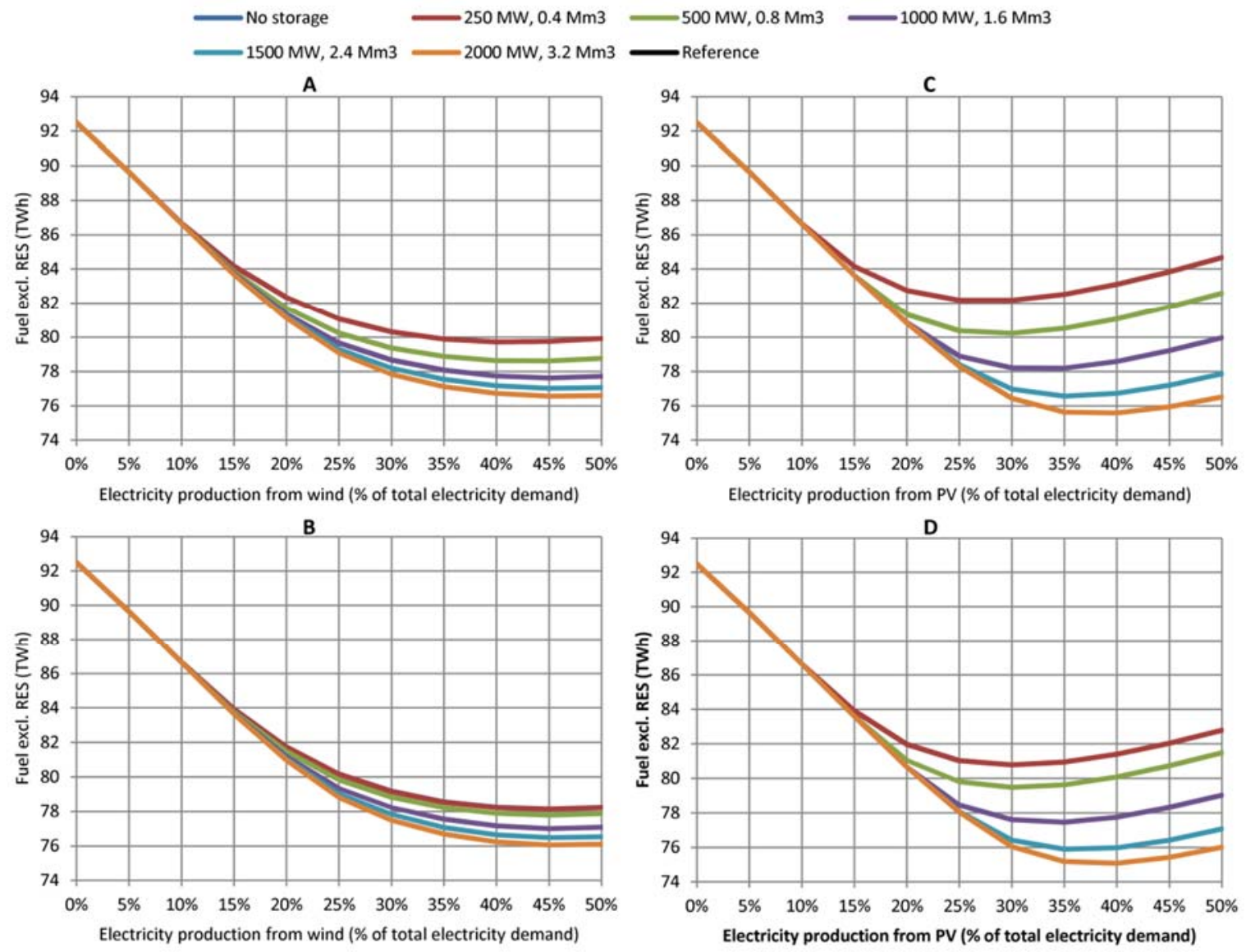

Figure 6 Fuel consumption excluding RES for scenarios with wind plus standard (A) and flexible desalination (B) and PV with standard (C) and flexible desalination (D)

Figure 7 presents the analysis of the $\mathrm{CO}_{2}$ emissions for all of the 24 created scenarios. The results here are similar to the ones regarding the total fuel consumption. It can be seen that that the increase in the penetration of both wind and PV helps to reduce $\mathrm{CO}_{2}$ emissions and that the implementation of larger BoPHS as well the utilization of a flexible desalination system can further help the reduction of the emissions. There is a similar increase in the emissions at certain higher penetrations of RES in the scenarios. The reason behind this is the same as with the fuel consumption. The lowest emissions were again observed in the scenario with a desalination plant with an installed capacity of $150 \%$, PV penetration of $40 \%$ and BoPHS with a power of $2000 \mathrm{MW}$. The emissions were 17.94 Mt annually in this case, $0.81 \mathrm{Mt}$ less than in the reference scenario. If we observe the emissions in a relation to the total electricity demand however, the difference is again much higher. The emissions for the scenario with desalination are equal to $0.8235 \mathrm{Mt} \mathrm{CO}_{2}$ per TWh of the total annual electricity demand, compared to $1.2917 \mathrm{Mt}$ for the reference scenario. This represents a decrease of close to $36 \%$. 

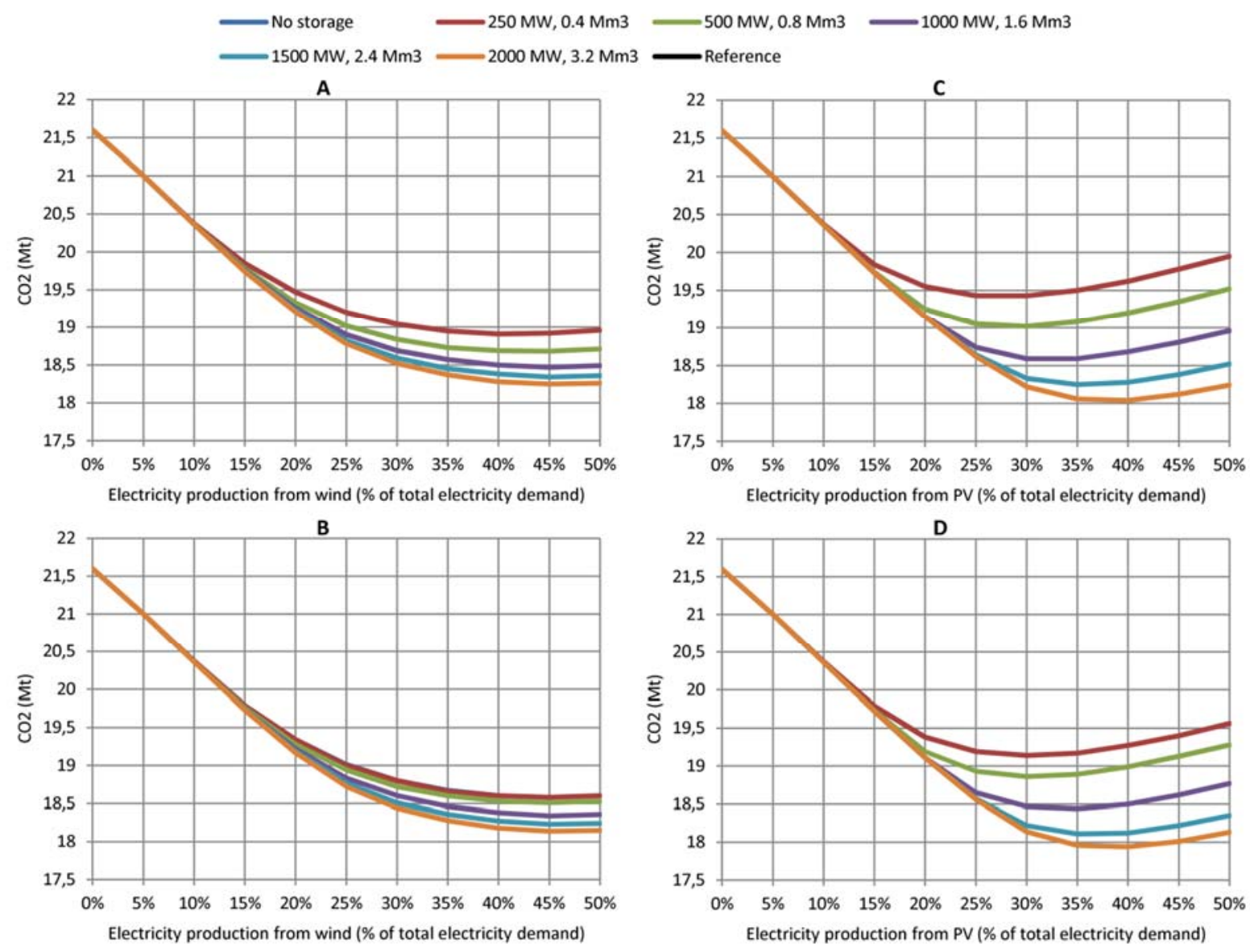

Figure $7 \mathrm{CO}_{2}$ emissions for scenarios with wind plus standard (A) and flexible desalination (B) and PV with standard (C) and flexible desalination (D)

\section{SENSITIVITY ANALYSIS}

In order to analyse the impact grid stabilization share, minimum power plant capacity (PP min) and the electricity consumption of the desalination unit have on the presented results a sensitivity analysis has been performed. These three parameters have all been altered from $50 \%$ to $+50 \%$ with a step of $10 \%$. Figure 8 presents the preformed sensitivity analysis. The analysis has been performed on a scenario with a desalination unit with a capacity of $65000 \mathrm{~m}^{3}$ of fresh water per hour (100\% capacity) and a BoPHS unit with an installed power of $1000 \mathrm{MW}$ and $1.6 \mathrm{Mm}^{3}$ of brine storage once for a penetration of wind power equalling $30 \%$ and once for the penetration of $\mathrm{PV}$ equalling $30 \%$. 

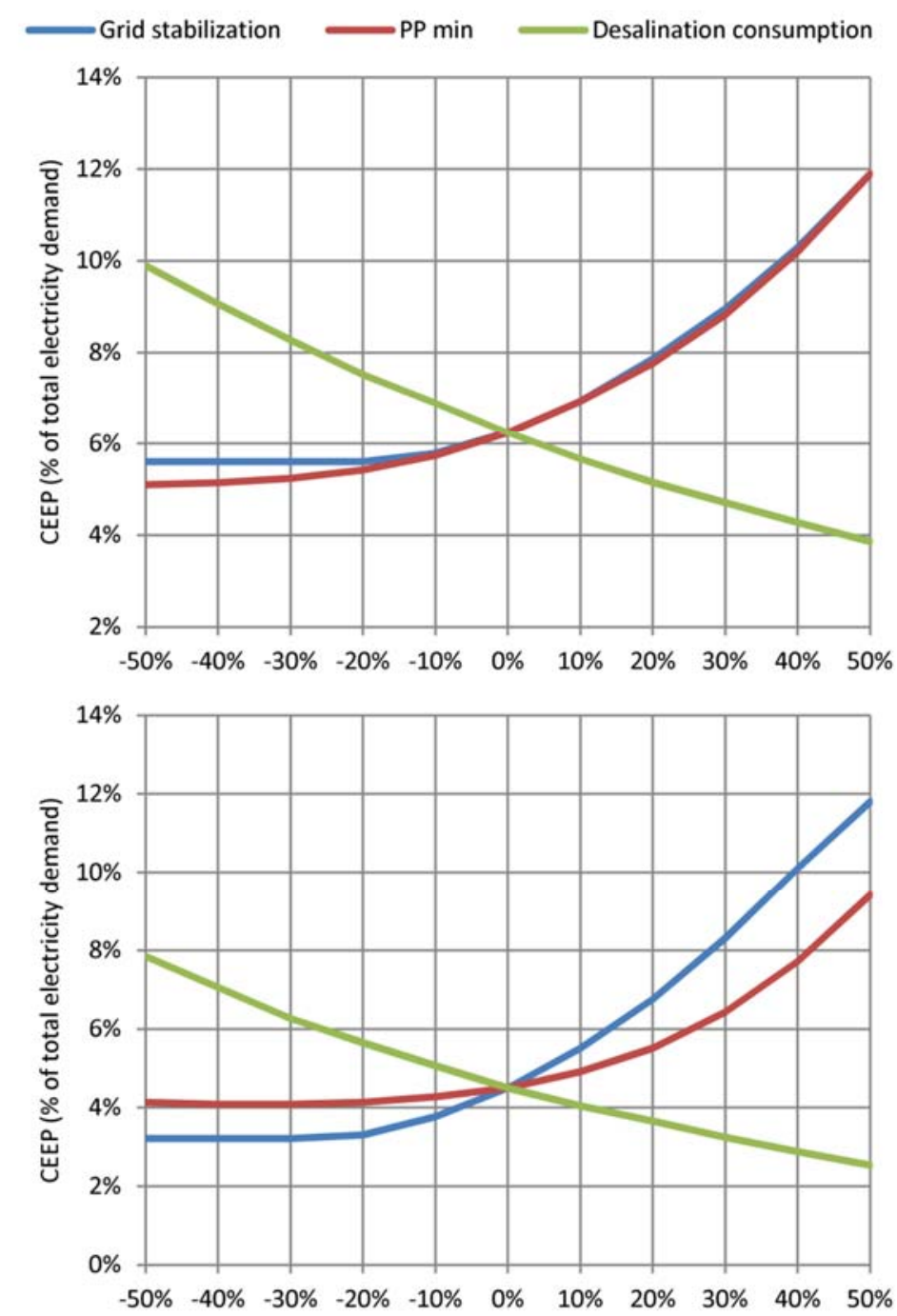

Figure 8 Sensitivity analysis for a scenario with wind (top) and PV (bottom)

The reduction of the grid stabilization share from $30 \%$ to $15 \%$ (a reduction of $50 \%$ ) has reduced CEEP from $6.25 \%$ to $5.6 \%$ in the case with wind power and from $4.5 \%$ to $3.22 \%$ in the case of $\mathrm{PV}$. The increase of the grid stabilization share to $45 \%$ (an increase of $50 \%$ ) has a much stronger influence increasing CEEP to $11.9 \%$ in the case of wind and $11.81 \%$ for PV. PP min has a similar tendency where its reduction from $1040 \mathrm{MW}$ to $520 \mathrm{MW}$ has reduced the amount of CEEP in the system to $5.1 \%$ and $4.13 \%$ for the cases with wind power and PV respectively. The increase of PP min to $1560 \mathrm{MW}$ has increased CEEP to $11.9 \%$ and $9.42 \%$. The electricity consumption of the desalination units has an opposite effect on CEEP when compared to the grid stabilization share and PP min. Its reduction by $50 \%$ from 7.98 to $3.99 \mathrm{kWh} / \mathrm{m}^{3}$ of fresh water has increased CEEP from $6.25 \%$ to $9.89 \%$ in the case of wind power and from $4.5 \%$ to $7.84 \%$ for PV while its increase to $11.97 \mathrm{kWh} / \mathrm{m}^{3}$ of fresh water (an increase of $50 \%$ ) has reduced CEEP to $3.87 \%$ and $2.54 \%$ respectively.

The preformed sensitivity analysis has shown that the observed parameters can have a significant impact on the end results of the created scenarios. The increase of the grid stabilization share and PP min greatly reduce the flexibility of the electricity system making it more difficult to achieve higher penetrations of intermittent RES like wind power and PV. Their reduction on the other hand has only a slight impact on the system. The decrease and increase 
of the electricity demand of the desalination plant can also influence CEEP greatly since it has a significant impact on the total electricity demand of the system.

\section{CONCLUSIONS}

The results of this paper demonstrate a positive effect of the implementation of desalination systems on the increase for the potential for the penetration of renewables. It can be seen from the results obtained in this case study that an increase of the flexibility of the desalination plant can greatly benefit the reduction of CEEP as can the utilization of BoPHS. The increased energy demand that occurs from the installation of RO desalination units can be satisfied by the implementation of RES like wind and PV. A higher penetration of RES will of course have a positive effect on the reduction of $\mathrm{CO}_{2}$ emissions and fuel consumption. The introduction of a desalination plant and a BoPHS system in the Jordanian energy system could increase the potential for the penetration of wind power to roughly 32\% and for PV power to roughly $37 \%$ of the total annual electricity demand.

The presented case study demonstrates that the implementation of RO desalination can greatly increase the water availability in Jordan. The demonstrated concept could provide an additional $95 \mathrm{~m}^{3}$ of fresh water per capita annually. If designed appropriately, the flexibility of the RO desalination in a combination with BoPHS could allow a high penetration of intermittent RES like wind and PV, for which Jordan has a lot of potential, which could supply the system with the necessary electricity. The integration of water and energy systems could provide a real benefit to the country of Jordan regarding its water supply, energy security and ecology.

\section{ACKNOWLEDGEMENTS}

Financial support from the European Union's seventh Programme managed by REA-Research Executive Agency http://ec.europa/rea (FP7/2007-2013) under Grant agreement PIRSES-GA2011-294933 (DISKNET project) is gratefully acknowledged.

\section{REFERENCES}

[1] “International Energy Agency,” [Online]. Available: http://iea.org/. [Accessed 28 January 2013].

[2] A. Al-Ghandoor, "Evaluation of energy use in Jordan using energy and exergy analyses," Energy and Buildings, no. 59, pp. 1-10, 2013.

[3] "Updated Master Strategy of Energy Sector in Jordan for the period (2007-2020)," 2007. [Online]. Available: http://www.nerc.gov.jo/Download/english\%20energy\%20strategy.pdf. [Accessed 16 January 2013].

[4] "Jordan's Department of Statistics," [Online]. Available: http://www.dos.gov.jo/. [Accessed 25 January 2013].

[5] Y. Anagreh, A. Bataineh and M. Al-Odat, "Assessment of renewable energy potential, at Aqaba in Jordan," Renewable and Sustainable Energy Reviews 14, p. 1347-1351, 2010.

[6] S. M. Habali, M. Amr, I. Saleh and R. Ta'ani, "Wind as an alternative source of energy in Jordan," Energy Conversion \& Management 42, pp. 339-357, 2001.

[7] E. S. Hrayshat, "Wind resource assessment of the Jordanian southern region," Renewable Energy 32, pp. 1948-1960, 2007. 
[8] M. S. Al-Soud and E. S. Hrayshat, "A 50MW concentrating solar power plant for Jordan,” Journal of Cleaner Production 17, pp. 625-635, 2009.

[9] E. S. Hrayshat and M. S. Al-Soud, "Solar energy in Jordan: current state and prospects," Renewable and Sustainable Energy Reviews 8, pp. 193-200, 2004.

[10] M. A. Alsaad, "Wind energy potential in selected areas in Jordan," Energy Conversion and Management 65, p. 704-708, 2013.

[11] E. S. Hrayshat, "Viability of solar photovoltaics as an electricity generation source for Jordan," Renewable Energy 34, pp. 2133-2140, 2009.

[12] E. Denny, K. Donnelly, R. McKay, G. Ponte and T. Uetake, "Sustainable Water Strategies for Jordan," $2008 . \quad$ [Online]. Available: http://www.umich.edu/ ipolicy/IEDP/2008jordan/IEDP\%20Jordan\%20\%20Water\%20Strategies.pdf. [Accessed 20 January 2013].

[13] R. A. A. Khaleq, "Water Demand Management in Jordan," 2008. [Online]. Available: http://www.semide.net/media_server/files/5/J/200806_WDM_Jordan.pdf. [Accessed 20 January 2013].

[14] "Water for Life Jordan's Water Strategy 2008-2022," 2009. [Online]. Available: http://data.unhcr.org/syrianrefugees/admin/download.php?id=4230. [Accessed 20 January 2013].

[15] N. Hadadin, M. Qaqish, E. Akawwi and A. Bdour, "Water shortage in Jordan Sustainable solutions," Desalination 250, p. 197-202, 2010.

[16] "Drought in the Arab World," 2007. [Online]. Available: http://css.escwa.org.lb/sdpd/3010_1-11/D6.pdf. [Accessed 20 January 2013].

[17] M. Beyth, "The Red Sea and the Mediterranean-Dead Sea canal project," Desalination 214, pp. 365-371, 2007.

[18] T. Novosel, B. Ćosić, G. Krajačić, S. M. Mohsen and N. Duić, "The importance of Jordan's Red Sea-Dead Sea project for the integration of high share of intermittent renewable energy sources," in Proceedings of 7th Conference on Sustainable Development of Energy, Water and Environment Systems - SDEWES Conference, Skopje, 2012.

[19] T. Novosel, B. Ćosić, G. Krajačić, N. Duić, H. Lund, V. B. Mathiesen, S. M. Mohsen, S. M. Ashhab and K. A. Ababneh, "The desalination module in the EnergyPLAN advanced energy system analyses tool: a case study for Jordan," in International Conference on Integrated Renewable Energy, Desalination and Water Supply - IREDeW, Amman, 2013.

[20] S. Filin, Y. Avni, A. Baruch, S. Morik, R. Arav and S. Marco, "Characterization of land degradation along the receding Dead Sea coastal zone using airborne laser scanning," Geomorphology, vol. 206, pp. 403-420, 2014.

[21] B. Peñate and L. García-Rodríguez, "Current trends and future prospects in the design of seawater reverse osmosis desalination technology," Desalination, no. 284, pp. 1-8, 2012.

[22] M. S. Mohsen and O. R. A1-Jayyousi, "Brackish water desalination: an alternative for water supply enhancement in Jordan," Desalination, no. 124, pp. 163-174, 1999.

[23] M. S. Miranda and D. Infield, "A wind-powered seawater reverse-osmosis system without batteries," Desalination, no. 153, pp. 9-16, 2002.

[24] B. Peñate, F. Castellano, A. Bello and L. García-Rodríguez, “Assessment of a stand-alone gradual capacity reverse osmosis desalination plant to adapt to wind power availability: A case study," Energy, no. 36, pp. 4372-4384, 2011. 
[25] D. Herold and A. Neskakis, "A small PV-driven reverse osmosis desalination plant on the island of Gran Canaria," Desalination, no. 137, pp. 285-292, 2011.

[26] T. Espino, B. Peeate, G. Piernavieja, D. Herold and A. Neskakis, "Optimised desalination of seawater by a PV powered reverse osmosis plant for a decentralised coastal water supply," Desalination, no. 156, pp. 349-350, 2003.

[27] A. Joyce, D. Loureiro, C. Rodrigues and S. Castro, "Small reverse osmosis units using PV systems for water purification in rural places," Desalination, no. 137, pp. 39-44, 2001.

[28] "EnergyPLAN," [Online]. Available: http://energy.plan.aau.dk/. [Accessed 12 February 2013].

[29] National Electric Power Company, "Annual Report 2009," 2010. [Online]. Available: http://www.nepco.com.jo/store/docs/web/2009_en.pdf. [Accessed 16 January 2013].

[30] B. Ćosić, G. Krajačić and N. Duić, “A 100\% renewable energy system in the year 2050: The case of Macedonia," Energy, vol. 48, no. 1, pp. 80-87, 2012.

[31] W. Liu, H. Lund and B. V. Mathiesen, "Large-scale integration of wind power into the existing Chinese energy system,” Energy, vol. 36, no. 8, p. 4753-4760, 2011.

[32] H. Lund and W. Kempton, "Integration of renewable energy into the transport and electricity sectors through V2G," Energy Policy, vol. 36, no. 9, p. 3578-3587, 2008.

[33] M. Munster and H. Lund, "Use of waste for heat, electricity and transport - Challenges when performing energy system analysis," Energy, no. 34, pp. 636-644, 2009.

[34] H. Lund, "Large-scale integration of optimal combinations of PV, wind and wave power into the electricity supply," Renewable Energy, no. 31, pp. 503-515, 2006.

[35] H. Lund and E. Munster, "Modelling of energy systems with a high percentage of CHP and wind power," Renewable Energy, vol. 28, no. 14, pp. 2197-2193, 2003.

[36] B. Ćosić, N. Markovska, G. Krajačić, V. Taseska and N. Duić, "Environmental and economic aspects of higher RES penetration into Macedonian power system," Applied Thermal Engineering, vol. 43, pp. 158-162, 2012.

[37] H. Lund and B. V. Mathiesen, "Energy system analysis of 100\% renewable energy systems - The case of Denmark in years 2030 and 2050," Energy, vol. 34, no. 5, pp. 524$531,2009$.

[38] G. Krajačić, N. Duić, Z. Zmijarević, B. V. Mathiesen, A. A. Vučinić and M. G. Carvalho, "Planning for a $100 \%$ independent energy system based on smart energy storage for integration of renewables and $\mathrm{CO} 2$ emissions reduction," Applied Thermal Engineerin, vol. 31, no. 13, pp. 2073-2083, 2011.

[39] "H2RES Model," [Online]. Available: http://powerlab.fsb.hr/h2res/. [Accessed 12 February 12].

[40] H. Lund, "EnergyPLAN Advanced Energy Systems Analysis Computer Model Documentation Version 11.0," September 2013. [Online]. Available: http://www.energyplan.eu/wp-content/uploads/2013/06/EnergyPLAN-DocumentationV11-2013.pdf. [Accessed 26 October 2013].

[41] "NEPCO," [Online]. Available: http://www.nepco.com.jo/. [Accessed 13 February 2013].

[42] "meteonorm," [Online]. Available: http://meteonorm.com/. [Accessed 14 February 2013].

[43] B. Ćosić, N. Markovska, V. Taseska, G. Krajačić and N. Duić, "Increasing the renewable energy sources absorption capacity of the Macedonian energy system," Journal of Renewable and Sustainable Energy, vol. 5, no. 4, 2013. 
[44] I. B. Bjelić, N. Rajaković, B. Ćosić and N. Duić, "Increasing wind power penetration into the existing Serbian energy system," Energy, vol. 57, pp. 30-37, 2013. 